\title{
The non-homologous end-joining activity is required for Fanconi anemia fetal HSC maintenance
}

\author{
Yan Nie ${ }^{1}$, Yibo Li ${ }^{1}$, Xiaoli Li ${ }^{1}$, Andrew F. Wilson ${ }^{1}$ and Qishen Pang ${ }^{1,2^{*}}$ (D)
}

\begin{abstract}
Background: Recent studies have shown that deficiency in the Fanconi anemia (FA) DNA repair pathway enhances the error-prone non-homologous end-joining (NHEJ) repair, leading to increased genomic instability, and that genetic or pharmacological inhibition of the NHEJ pathway could rescue the FA phenotype.

Methods: First, we exposed LSK cells from WT and Fanca $^{-/}$mice to DNA-PKcs inhibitor NU7026 or Ku70 knockdown to examine whether inhibition of NHEJ sensitizes Fanca ${ }^{-/-}$HSPCs to PARP inhibitor (PARPi)- or interstrand crosslinking (ICL)-induced cell death and genomic instability. We then generated DNA-PKC ${ }^{3 \mathrm{~A} / 3 A} \mathrm{Fanca}^{-/-}$mice to investigate the effect of specific inactivation of NHEJ on fetal HSCs. Lastly, we used two p53 mutant models to test whether specific inactivation of the p53 function in apoptosis is sufficient to rescue embryonic lethality and fetal HSC depletion in Fanca $^{-/-}$DNA-PKCS ${ }^{3 A 3 A}$ mice.
\end{abstract}

Results: Inhibition of NHEJ sensitizes HSPCs from $\mathrm{Fanca}^{-/-}$mice to PARP inhibition- and ICL-induced cell death and genomic instability and further decreases $\mathrm{Fanca}^{-/-} \mathrm{HSPC}$ proliferation and hematopoietic repopulation in irradiated transplant recipients. Specific inactivation of NHEJ activity by the knockin DNA-PKCs ${ }^{3 A 3 A}$ mutation in two FA mouse models, $\mathrm{FanCa}^{-/-}$and $\mathrm{FanCC}^{-1-}$, leads to embryonic lethality. DNA-PKCS ${ }^{3 \mathrm{~A} 3 \mathrm{~A}}$ causes fetal HSC depletion in developing Fanca $^{-1-}$ embryos due to increased HSC apoptosis and cycling. Both $p 53^{-/-}$and a knockin $p 53^{515 C}$ mutation, which selectively impairs the 053 function in apoptosis, can rescue embryonic lethality and fetal HSC depletion in Fanca ${ }^{-1-}$ DNA-PKCS ${ }^{3 A 3 A}$ mice.

Conclusion: These results demonstrate that the NHEJ pathway functions to maintain Fanconi anemia fetal HSCs.

Keywords: Fanconi anemia (FA), Hematopoietic stem cells (HSCs), Homologous recombination (HR), Non-homologous end joining (NHEJ)

\section{Background}

Fanconi anemia (FA) is a genetic disorder associated with bone marrow (BM) failure and malignancies including leukemia and solid cancers [1-4]. Mutations in any of the 22 FA genes (FANCA-W) lead to clinical manifestations characterized by developmental abnormalities, progressive bone marrow failure (BMF), and a high risk of developing cancer including leukemia [5-8]. At the cellular level, FA is characterized by chromosomal

\footnotetext{
* Correspondence: Qishen.Pang@cchmc.org

${ }^{1}$ Division of Experimental Hematology and Cancer Biology, Cincinnati Children's Hospital Medical Center, 3333 Burnet Avenue, Cincinnati, OH 45229, USA

${ }^{2}$ Department of Pediatrics, University of Cincinnati College of Medicine, Cincinnati, OH 45229, USA
}

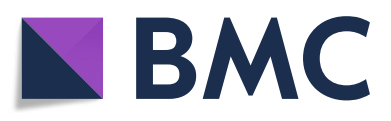

(c) The Author(s). 2019 Open Access This article is distributed under the terms of the Creative Commons Attribution 4.0 International License (http://creativecommons.org/licenses/by/4.0/), which permits unrestricted use, distribution, and reproduction in any medium, provided you give appropriate credit to the original author(s) and the source, provide a link to the Creative Commons license, and indicate if changes were made. The Creative Commons Public Domain Dedication waiver (http://creativecommons.org/publicdomain/zero/1.0/) applies to the data made available in this article, unless otherwise stated. serves as a clinical diagnostic hallmark of EA [1-4]. At serves as a clinical diagnostic hall ark of FA [1-4]. At the molecular level, eight FA proteins (FANCA, $-\mathrm{B},-\mathrm{C}$, $-E,-F,-G,-L$, and $-M$ ), along with other associated factors, form the FA core complex in response to DNA damage or replicative stress, which acts in part as an ubiquitin ligase. This FA core complex monoubiquitinates two downstream FA proteins, FANCD2 and FANCI, which then recruit other downstream FA proteins including several key proteins involved in homologous recombination (HR) repair, and possibly other DNA repair factors, to nuclear loci containing damaged DNA and consequently influence important cellular processes such 
as DNA replication, cell-cycle control, and DNA damage response and repair [9-11].

Recent studies suggested that the FA pathway promotes the error-free HR repair pathway while suppressing the error-prone non-homologous end-joining (NHEJ) pathway [12-15]. Using FA-deficient Caenorhabditis elegans, chicken and human cells, two studies demonstrated that FA deficiency enhanced the error-prone NHEJ repair, leading to increased genomic instability [12, 15]. These studies also showed that genetic or pharmacological inhibition of the NHEJ pathway could rescue the FA phenotype. Another similar study showed that inhibition of the NHEJ ligase, LIG4, ameliorated the FA phenotype, but had no effect on BRCA1 deficiency [16]. It appears the FA pathway may act to prevent inappropriate recruitment of NHEJ factors to sites of DNA damage. However, the exact mechanism by which the FA pathway counteracts the NHEJ pathway is largely unknown.

A clinical application of HR-NHEJ interaction is synthetic lethality induced by poly (ADP-ribose) polymerase (PARP) inhibition in BRCA1/2-mutated cancer [17, 18]. Since PARP functions as a critical sensor of single-strand breaks (SSBs) in base-excision repair, as a mediator for restarting stalled replication forks of HR-mediated doublestrand break (DSB) repair, and as a means of preventing the binding of Ku proteins to DNA ends in NHEJ pathway [19-22], therefore, blocking the ADP-ribosylation activity with small molecules can achieve synthetic lethality with DNA-damaging agents in the treatment of certain cancers [23-29]. It has been shown that PARP inhibitors could selectively target cancer cells with a defective HR repair of DSB [25]. For example, BRCA1-, BRCA2-, and ATM-deficient cells show hypersensitivity to PARP inhibitors, leading to genomic instability and eventual cell death due to the development of non-viable genetic errors generated by the error-prone NHEJ repair [26-28].

In the current study, we show that inhibition of NHEJ sensitizes $\mathrm{Fanca}^{-/-}$HSPCs from mice to PARP inhibitioninduced cell death and genomic instability and leads to a further decrease in the proliferation and hematopoietic repopulation of the $\mathrm{Fanca}^{-/-}$HSPCs. We also show that simultaneous inactivation of DNA-PKcs and Fanca or Fancc causes embryonic lethality in mice, which can be rescued by the apoptosis-defective p53 mutation. Furthermore, using the knockin $D N A-P K c s^{3 A / 3 A}$ model, which specifically inactivates the NHEJ activity of DNA-PKcs, we demonstrate that the NHEJ activity of DAN-PKCs is required for FA fetal HSC maintenance.

\section{Methods}

Mice and treatment

$\mathrm{Fanca}^{-/-}$and $\mathrm{Fancc}^{-/-}$mice [30, 31] were generated by interbreeding the heterozygous $\mathrm{Fanca}^{+/-}$(Dr. Madeleine
Carreau at Laval University) or $\mathrm{Fancc}^{+/-}$mice (Dr. Manuel Buchwald, University of Toronto), respectively. $p 53^{515 C / 515 C}$ mice (provided by Dr. Guillermina Lozano at University of Texas M.D. Anderson Cancer Center) [32] or DNA$P K$ Cs $^{3 A / 3 A}$ mice (provided by Dr. Benjamin P. C. Chen at University of Texas Southwestern Medical Center) [33] were generated by interbreeding heterozygous $p 53^{+/ 515 C}$ or DNA-PKcs ${ }^{+/ 3 A}$ mice, respectively. All the animals including BoyJ mice were maintained in the animal barrier facility at Cincinnati Children's Hospital Medical Center. All animal experiments were performed in accordance with the institutional guidelines and approved by the Institutional Animal Care and Use Committee of Cincinnati Children's Hospital Medical Center (IACUC2018-0006).

\section{Isolation of bone marrow cells and flow cytometry analysis}

The femora and tibiae were harvested from the mice immediately after their sacrifice with $\mathrm{CO}_{2}$. Bone marrow (BM) cells were flushed from bones into Iscove's modified Dulbecco's medium (IMDM; Invitrogen) containing 10\% FCS, using a 21-gauge needle and syringe. Low-density BM mononuclear cells (LDBMMNCs) were separated by Ficoll Hypaque density gradient (Sigma-Aldrich, St. Louis, $\mathrm{MO}$ ) and washed with IMDM medium.

For flow analysis and cell sorting, the lineage marker (Lin) mixture (BD Biosciences, San Jose, CA) for BM cells from treated or untreated mice included the following biotinylated antibodies: CD3 $\varepsilon(145-2 \mathrm{C} 11), \mathrm{CD} 11 \mathrm{~b}$ (M1/70), CD45R/B220 (RA3-6B2), and mouse erythroid cells Ly-76 (Ter119), Ly6G, and Ly-6C (RB6-8C5). Other conjugated antibodies (BD Biosciences, San Jose, CA) used for surface staining included CD45.1 (A20), CD45.2 (A104), Sca1 (D7), c-kit (2B8), CD48 (HM48-1), and CD150 (9D1). Biotinylated primary antibodies were detected by incubation of antibody-coated cells with streptavidin-PerCP or FITC (BD Biosciences, San Jose, $\mathrm{CA}$ ) in a two-step staining procedure. For the detection of fetal liver HSCs, whole fetal liver cells were incubated with FITC-conjugated antibody to CD41 (MWReg30), CD48 (HM48-1-PE), Ter119 (Ter119), PE-conjugated antibody to CD150 (26D12:DNAX), APC-conjugated Mac1 (M1/70), and biotin-conjugated Sca1 (Ly6A/E-biotin), followed by staining with streptavidin conjugated to APC-Cy7 (PharRed, PR; Becton Dickinson). For BM transplantation experiments, pacific blue-conjugated CD45.2 (A104, BioLegend, San Diego, CA) was used to determine donor-derived cells. For cell sorting, lineagenegative cells were enriched using lineage depletion reagents (StemCell Technologies) according to the manufacturer's instruction. The Lin-negative and LSK populations were acquired by using the FACSAria II sorter (BD Biosciences). 


\section{In vitro cell culture and treatment}

Briefly, LSK cells were maintained in StemSpan medium supplemented with $50 \mathrm{ng} / \mathrm{ml}$ murine rTpo (Preprotech, Rocky Hill, NJ), $50 \mathrm{ng} / \mathrm{ml}$ murine rSCF (Preprotech, Rocky Hill, NJ), and $1 \%$ BSA at $37{ }^{\circ} \mathrm{C}$ in normoxia (21\% $\left.\mathrm{O}_{2}, 5 \% \mathrm{CO}_{2}\right)$. Cells with the indicated genotype were treated with increasing doses of DNA-PKcs inhibitor NU7026 (0-100 $\mu$ M; Sigma-Aldrich, St Louis, MO), PARP inhibitor KU58948 (1 $\mu \mathrm{M}$; Axon Medchem), or mitomycin C (0-1.0 $\mu \mathrm{M}$; Sigma-Aldrich, St Louis, MO) for $36 \mathrm{~h}$ followed by survival and chromosomal breakage analyses.

\section{Ku70 knockdown by lentiviral short hairpin RNA}

Hairpin sequence for scramble control (CTCGCTTGG GCGAGAGTAA) or Ku70-1 (CCCAGAGTGTGTAC ACCAGTAA), Ku70-2 (CCGTCAGATTGTGCTGGAG AAA), and Ku70-3 (ACGACACAGGTGGAGAATA TAA) was cloned into SFLV-eGFP-shRNA vector (Dr. Lenhand Rudolph (Institute of Molecular Medicine and Max-Planck-Research, Germany). The plasmids (10 $\mu \mathrm{g}$ each) were used to produce retroviral supernatant. LSK cells were transduced with the lentiviral supernatants in various volumes $(5,10,20,40$, and $80 \mu \mathrm{L})$. Protein was harvested $48 \mathrm{~h}$ after transduction and used for Western blot analysis of $\mathrm{Ku}-70$ using anti-Ku70 mouse monoclonal antibody (mab-Ku70, 3114-500, Abcam).

\section{Chromosomal breakage analysis}

Chromosome breakage analysis was performed on LSK cells as previously described [34]. Briefly, cells were treated with $0.05 \mathrm{mg} / \mathrm{ml}$ colcermid (Gibco, Grand Island, NY, USA) for $90 \mathrm{~min}$, followed by $0.4 \% \mathrm{KCl}$ hypotonic solution at $37^{\circ}$ for $20 \mathrm{~min}$, fixed with methanol and acetic acid at $4^{\circ}$ for $15 \mathrm{~min}$, and dropped onto microscope slides. The cells were then rinsed with isoton, stained with Giemsa for $5 \mathrm{~min}$, and rinsed with Gurr Buffer (CTL Scientific, Deer Park, NY, USA) and Milli-Q-filtered deionized water. A total of 50 cells from each sample were scored for chromosome aberrations.

\section{Bone marrow transplantation (BMT)}

One thousand to 2000 LSK cells $\left(\mathrm{CD} 45.2^{+}\right)$, along with 200,000 c-Kit-depleted protector cells, were transplanted into lethally irradiated Boyj $\left(\mathrm{CD} 45.1^{+}\right)$mice. The recipients were subjected to flow cytometric analysis for donor-derived LSK cells 16 weeks after BMT. In other experiments, 2000 GFP-sorted scramble shRNA or Ku70 shRNA lentiviral vector-transduced LSK cells, along with 200,000 c-Kit-depleted protector cells, were transplanted into lethally irradiated Boyl mice. The recipients were subjected to flow cytometric analysis for donor-derived LSK cells 16 weeks after BMT.

\section{Cell-cycle and apoptosis analysis}

To analyze the cell-cycle status of the HSC subsets, bone marrow cells were initially stained with antibodies against $\mathrm{Lin}^{+}$cells, C-KIT, SCA-1, CD150, and CD48 as described above. After incubation with these cell surface antibodies, the cells underwent fixation and permeabilization with transcription factor buffer set (BD Biosciences, \#562725) according to the manufacturer's instruction. After fixation, cells were incubated with APC-anti-Ki67 (BD Biosciences, \#558615), washed and stained with PI. Cells were analyzed by flow cytometry. For the apoptosis detection, bone marrow cells were stained with the antibodies for the HSC surface markers and then stained with APC-Annexin V (BD Biosciences, \#550474) and 7 AAD. Annexin V-positive populations were determined as apoptotic cells using the FACS LSR II (BD Biosciences).

\section{Colony-forming unit assay}

For the in vitro colony-forming unit (CFU) assay, 1000 sorted LSK cells were seeded in MethoCult GF M3434 (STEMCELL Technologies) according to the manufacturer's recommendations. Colonies were visualized and counted at day 7. The experiment was performed in triplicate for each sample.

\section{Statistical analysis}

Student's $t$ test was performed using GraphPad Prism v6 (GraphPad software). Comparison of more than two groups was analyzed by one-way ANOVA test. Values of $p<0.05$ were considered statistically significant. Results are presented as mean \pm SD. “*”" indicates $p<0.05$; “*:*”, $p<0.01 ;$ and “****", $p<0.001$.

\section{Results}

Inhibition of NHEJ sensitizes Fanca ${ }^{-/}$HSPCs to PARPiinduced cell death and genomic instability

To understand the mechanism by which the FA pathway counteracts NHEJ in genomic maintenance in HSPCs,

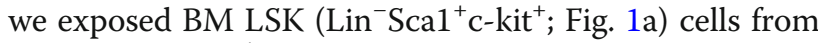
WT and $\mathrm{Fanca}^{-/-}$mice to DNA-PKcs inhibitor NU7026 or Ku70 knockdown in the presence of PARP inhibitor KU58948. The reason for PARP inhibition was that we and others have shown that PARP inhibition could greatly boost NHEJ activity in HR-deficient cells including FA HSPCs $[28,29,35]$. Both WT and $\mathrm{Fanca}^{-/-}$LSK cells were not sensitive to the PARP inhibitor (Fig. 1b). However, treatment with the DNA-PKcs inhibitor NU7026 sensitized the $\mathrm{Fanca}^{-/-}$LSK cells to PARPi-induced cell death at low doses $(0.1-1 \mu \mathrm{M})$, which had no effect on WT cells (Fig. 1b). Furthermore, inhibition of DNA-PKcs exacerbated genomic instability (chromosome and chromatid breaks, and radial chromosomes) in $\mathrm{Fanca}^{-/-}$LSK cells 


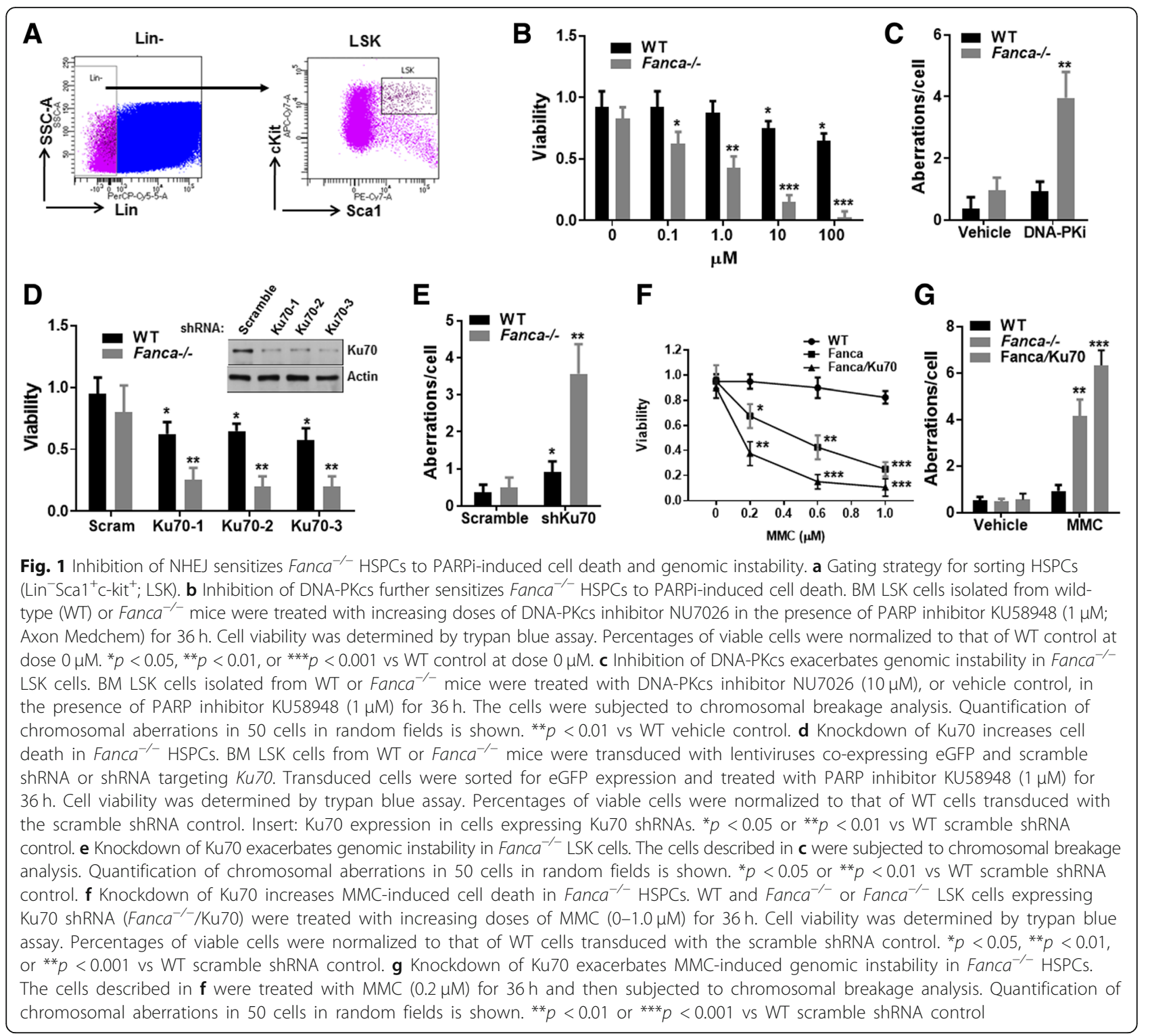

(Fig. 1c). We also genetically inhibited NHEJ by knocking down Ku70 expression using lentiviral shRNAs (Fig. 1d). We found that knockdown of Ku70 caused much higher levels of cell death (Fig. 1d) and chromosome aberrations (Fig. 1e) in Fanca $^{-1-}$ LSK cells than in WT cells. Furthermore, we treated BM LSK cells from WT and $\mathrm{Fanca}^{-/-}$mice with DNA cross-linker mitomycin $\mathrm{C}$ (MMC), which induces interstrand crosslinking (ICL), and found that knockdown of Ku70 caused much higher levels of cell death (Fig. 1d) and chromosome aberrations (Fig. 1e) in $\mathrm{Fanca}^{-/-}$LSK cells compared to $\mathrm{Fanca}^{-/-}$mock control cells. Together, these results suggest that the NHEJ pathway actually contributes to cell survival and genomic maintenance in Fanca $^{-/-}$HSPCs.

\section{Inhibition of NHEJ further decreases $\mathrm{Fanca}^{-/-}$HSPC renewal and repopulation}

We next determined the effect of NHEJ inhibition on the proliferation of $\mathrm{Fanca}^{-1-}$ HSPCs using the in vitro colony-forming unit (CFU) assay and the in vivo hematopoietic repopulation assay. Inhibition of NHEJ by the DNA-PKCs inhibitor NU7026 further reduced the capacity of $\mathrm{Fanca}^{-/-}$LSK cells to produced colony formation units when plated in methylcellulose supplemented with hematopoietic cytokines (Fig. 2a) and decreased the potential of these cells to proliferate in irradiated transplant recipients (Fig. 2b). Similar results were obtained with the $\mathrm{Fanca}^{-/-}$LSK cells that had been subjected to knockdown of Ku70 (Fig. 2c, d). Specifically, knocking down Ku70 further compromised the ability of 

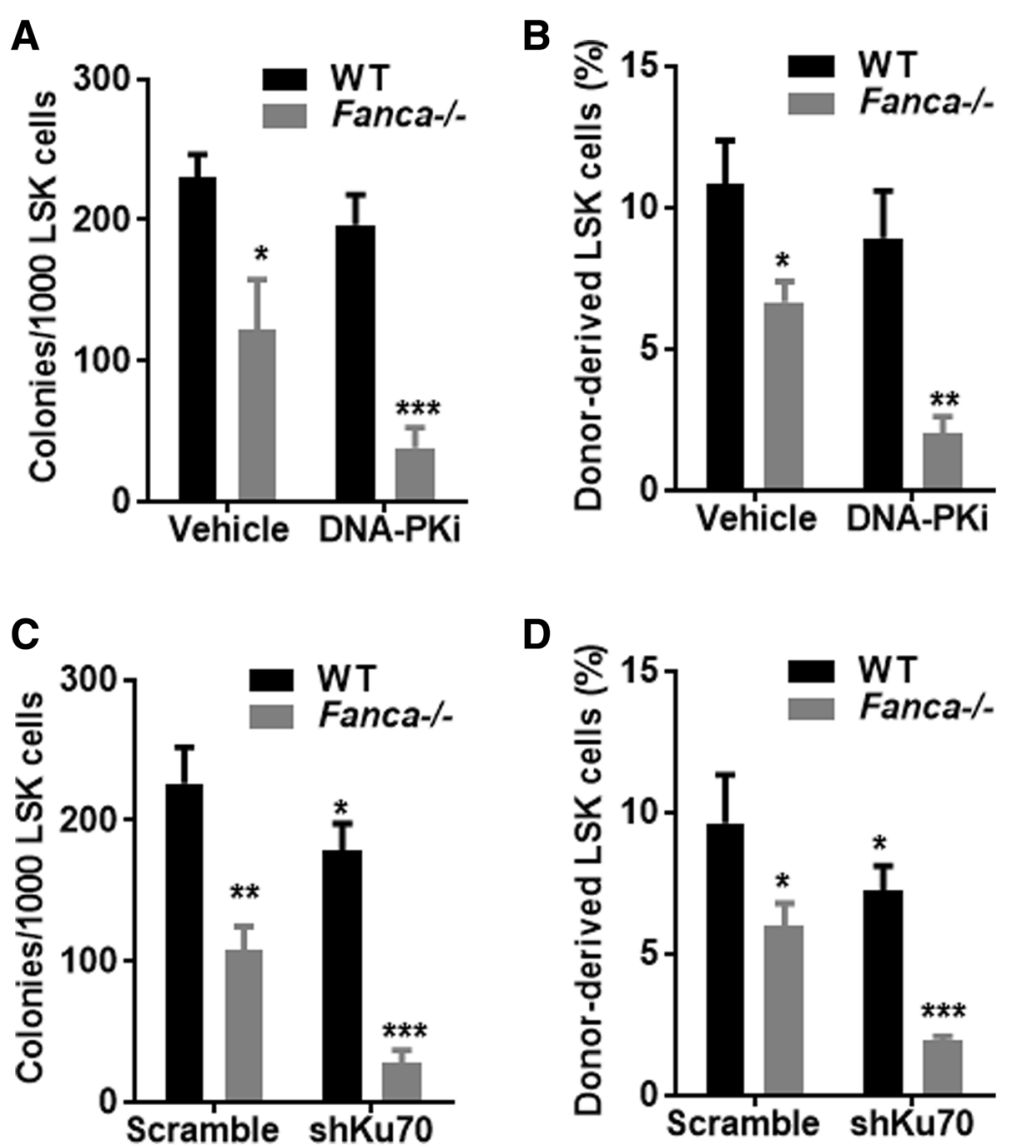

Fig. 2 Inhibition of NHEJ further decreases Fanca ${ }^{-/-}$HSC renewal and repopulation. a Inhibition of DNA-PKCs further decreases Fanca ${ }^{-/-}$HSPC proliferation. BM LSK cells isolated from WT or $\mathrm{Fanca}^{-/-}$mice were treated with DNA-PKcs inhibitor NU7026 (10 $\left.\mu \mathrm{M}\right)$ for $36 \mathrm{~h}$ and then plated in cytokine-supplemented methylcellulose medium. Colonies were enumerated on day 7 after plating. Results are means \pm standard deviation (SD) of three independent experiments. ${ }^{*} p<0.05$ or ${ }^{* * *} p<0.001$ vs WT vehicle control. b Inhibition of DNA-PKcs further compromises the repopulating capacity of Fanca ${ }^{-1-}$ HSPCs. BM LSK cells isolated from WT or Fanca ${ }^{-/-}$mice were treated with DNA-PKcs inhibitor NU7026 (10 $\mu$ M) for $36 \mathrm{~h}$. Two thousand LSK cells, along with 200,000 c-Kit-depleted protector cells, were then transplanted into lethally irradiated BoyJ mice. The recipients were subjected to flow cytometric analysis for donor-derived LSK cells 16 weeks after BMT ( $n=9-12$ per group). ${ }^{*} p<0.05$ or ${ }^{* *} p<0.01$ vs WT vehicle control. c Knockdown of Ku70 further decreases Fanca ${ }^{-1-}$ HSPC proliferation. BM LSK cells from WT or Fanca ${ }^{-1-}$ mice were transduced with lentiviruses co-expressing eGFP and scramble shRNA or shRNA targeting Ku70. Transduced cells were sorted for eGFP expression and then plated in cytokine-supplemented methylcellulose medium. Colonies were enumerated on day 7 after plating. Results are means \pm standard deviation (SD) of three independent experiments. ${ }^{*} p<0.05,{ }^{* *} p<0.01$, or ${ }^{* * *} p<0.001$ vs WT scramble shRNA control. d Knockdown of Ku70 compromises the repopulating capacity of $\mathrm{Fanca}^{-1-}$ HSPCs. Two thousand LSK cells described in c, along with 200,000 c-Kit-depleted protector cells, were then transplanted into lethally irradiated BoyJ mice. The recipients were subjected to flow cytometric analysis for donorderived LSK cells 16 weeks after BMT ( $n=9$ per group). ${ }^{*} p<0.05$ or ${ }^{* * *} p<0.001$ vs WT scramble shRNA control

Fanca $^{-/-}$LSK cells to form colony in the absence of stromal support (Fig. 2c) and to repopulate the transplant recipient mice (Fig. 2d). Taken together, these results indicate a crucial role of NHEJ in maintaining $\mathrm{Fanca}^{-/-}$ HSPC proliferation.

Inactivation of the NHEJ activity of DNA-PKcs in Fanca $^{-/-}$ or Fancc $^{-1-}$ mice leads to embryonic lethality

The observation that inhibition of NHEJ exacerbated genomic instability in $\mathrm{Fanca}^{-/-}$HSPCs appears to be conflict with previous reports that inhibition of the key NHEJ factors such as $\mathrm{Ku}$, Lig4, or DNA-PKcs could ameliorate the sensitivity of FA cells to interstrand crosslinking agents $[12,15]$. This prompted us to determine the in vivo effect of NHEJ inhibition in $\mathrm{Fanca}^{-/}$ mice. We crossed the $\mathrm{Fanca}^{-/-}$mice with a strain carrying the knockin $D N A-P K c s^{3 A / 3 A}$ mutation, which selectively inactivates the NHEJ activity but does not affect the kinase activity of DNA-PKcs [33]. To exclude the probability that the identified phenotypes might be due to a specific effect of a particular FA complementation group, we also employed an additional FA ( $\left.\mathrm{Fancc}^{-1-}\right)$ mouse model. Screening more than 160 E10.5 embryos and 270 pups showed that while we were able to obtain DNA-PKCs ${ }^{+/ 3 A} \mathrm{Fanca}^{-/-}$ and $D N A-P K C S^{+/ 3 A} \mathrm{Fancc}^{-/-}$pups, we found that 
DNA-PKcs ${ }^{3 A / 3 A} \mathrm{Fanca}^{-/-}$or DNA-PKcs ${ }^{3 A / 3 A} \mathrm{Fancc}^{-/-}$ double-deficient mice did not survive to birth (Tables 1 and 2). Thus, these results indicate that simultaneous inactivation of DNA-PKcs and Fanca or Fancc causes embryonic lethality in mice.

\section{DNA-PKcs ${ }^{3 A / 3 A}$ causes fetal HSC depletion in $\mathrm{Fanca}^{-/-}$ embryos due to increased HSC apoptosis and cycling} We next investigated the effect of DNA-PKcs-Fanca deficiencies on fetal hematopoiesis by examining the frequency of fetal HSCs $\left(\mathrm{CD} 150^{+} \mathrm{CD} 48^{-} \mathrm{Lin}^{-} \mathrm{Mac}^{-}{ }^{+} \mathrm{Sca}-1^{+}\right)$ in the E14.5 fetal liver of the mice, which has been shown to include all fetal liver HSC activity and are highly enriched for HSCs [36]. As shown in Fig. 3a, the frequency of fetal HSCs was more than four- to fivefold lower in DNA-PKCS ${ }^{3 A / 3 A} \mathrm{Fanca}^{-/-}$fetal livers compared to control samples from WT or single-deficient $\left(\mathrm{Fanca}^{-/-}\right.$or $D N A-P K c s^{3 A / 3 A}$ ) mice (Fig. 3a), indicating a phenotype of fetal HSC depletion.

Because we observed exacerbated cell death in $\mathrm{Fanca}^{-/-}$ LSK cells upon NHEJ inhibition (Fig. 1b, d), we wondered if increased apoptosis played a causal role in the depletion of fetal HSCs in DNA-PKcs ${ }^{3 A / 3 A} \mathrm{Fanca}^{-/-}$mice. To examine this possibility, we measured the apoptosis of fetal liver cells in WT, $\mathrm{Fanca}^{-/}, D N A-P K c S^{3 A / 3 A}$, and $D N A$ $\mathrm{PKCs}^{3 A / 3 A} \mathrm{Fanca}^{-/-}$embryos at E14.5 by Annexin V staining. Low levels (approximately 5\%) of apoptotic cells were observed in the livers of both WT and $\mathrm{Fanca}^{-/-}$ embryos (Fig. 3b). Whereas there was a significant increase in apoptotic fetal HSCs in DNA-PKCs ${ }^{3 A / 3 A}$ embryos compared to WT and Fanca ${ }^{-/-}$embryos, this increase was greatly exacerbated in $D N A-P K c s^{3 A / 3 A} \mathrm{Fanca}^{-/-}$ fetal livers (Fig. 3b). These results suggest that fetal HSC depletion observed in DNA-PKCS ${ }^{3 A / 3 A} \mathrm{Fanca}^{-/-}$mice may be caused by increased apoptosis. We also performed cell-cycle analysis to evaluate the effect of DNA-PKcs ${ }^{3 A / 3 A}$ on quiescence of $\mathrm{Fanca}^{-1-}$ fetal HSCs. We observed a statistically significant reduction of quiescent fetal HSCs in DNA-PKCS ${ }^{3 A / 3 A}$ and $\mathrm{Fanca}^{-/-}$embryos compared with WT embryos (Fig. 3c). Interestingly, a more dramatic decrease in quiescent fetal HSCs was detected in DNA-PKCs ${ }^{3 A / 3 A} \mathrm{Fanca}^{-/-}$embryos compared with the other three groups (Fig. 3c). These results suggest that the
NHEJ activity of DNA-PKcs and Fanca may play a quantitative or collaborative functional role in the cell cycle of fetal HSCs.

Inactivation of the p53 function in apoptosis is sufficient to rescue embryonic lethality and fetal HSC depletion in Fanca $^{-/}$DNA-PKCs ${ }^{3 A / 3 A}$ mice

Elevated p53 activation has been reported in the $D N A-P K c S^{3 A / 3 A}$ HSCs and FA HSPCs $[33,37]$. We thus asked whether p53-dependent apoptosis played a role in embryonic lethality and fetal HSC depletion in Fanca $^{-1-} D N A-P \mathrm{KCS}^{3 A / 3 A}$ mice. To this end, we bred $\mathrm{Fanca}^{+/} \mathrm{DNA}-\mathrm{PKCs}{ }^{+/ 3 A}$ mice to $p 53^{-/-}$animals and assessed the viability and development of the fetal HSCs. Because we observed increased HSC cycling in DNA-PKcs ${ }^{3 A / 3 A} \mathrm{Fanca}^{-/-}$embryos (Fig. 3c), we also crossed $\mathrm{Fanca}^{+-} \mathrm{DNA}-\mathrm{PKcs}{ }^{+/ 3 A}$ mice to a mutant $p 53$ mouse strain harboring a separation-of-function mutation in p53, $p 53^{515 C}$, in which its apoptotic function is abolished but its cell-cycle checkpoint activities remain intact [32]. The viability of $D N A-P K c s^{3 A / 3 A} \mathrm{Fanca}^{-/-}$mice was rescued by both $p 53$-null deficiency and the $p 53^{515 C}$ allele Fig. 4a, c). Furthermore, both the $p 53$-null and the $p 53^{515 C}$ allele were able to rescue fetal HSC depletion in Fanca $^{-/-} D N A-P K c s^{3 A / 3 A}$ embryos (Fig. 4b, d). Therefore, the p53-dependent apoptosis plays a causal role in embryonic lethality and fetal HSC depletion in Fanca $^{-/-} D N A-P K c S^{3 A / 3 A}$ mice.

\section{Discussion}

In the present study, we used multiple mouse models of closely related DNA damage response (FA, NHEJ, p53) pathways to show that inhibition of NHEJ sensitizes $\mathrm{Fanca}^{-/-}$HSPCs to PARPi-induced cell death and genomic instability. This surprising finding prompted us to propose that inhibition of the NHEJ pathway in FA HSPCs might actually exacerbate their sensitivity to DNA damage, which is the cellular hallmark of FA. In support of this notion, we showed that specific inactivation of the NHEJ activity of DNA-PKcs caused embryonic lethality in mice deficient for two components of the FA core complex Fanca and Fancc. Our results are in strike contrast to the studies reported by Adamo et al. [12] and Pace et al. [15] that hypersensitivity of

Table 1 Survival of $\mathrm{Fanca}^{-/-}$DNA-PKCS ${ }^{3 \mathrm{~A} / 3 A}$ embryos and pups

\begin{tabular}{|c|c|c|c|c|c|}
\hline \multicolumn{6}{|c|}{$\mathrm{DNA}-\mathrm{PKCS}^{+/ 3 A} \mathrm{Fanca}^{+/-} \times \mathrm{DNA}-\mathrm{PKCS}{ }^{+/ 3 A} \mathrm{Fanca}^{+/-}$intercross } \\
\hline & & $\begin{array}{l}\text { DNA-PKCs }{ }^{3 A / 3 A} \mathrm{Fanca}^{+/+} \text {or DNA-PKCs }{ }^{3 A} \\
\text { Fanca }^{+/-}\end{array}$ & $\begin{array}{l}\text { DNA-PKCS } \\
3 A \text { Fanca }{ }^{-/-}\end{array}$ & $\begin{array}{l}\text { DNA-PKCS } \\
\text { Fanca }^{-1-}\end{array}$ & $\begin{array}{l}\text { Other } \\
\text { genotypes }\end{array}$ \\
\hline \multirow{2}{*}{$\begin{array}{l}\text { E10.5 embryos ( } 96 \\
\text { screened) }\end{array}$} & Expected & 24 & 24 & 6 & 42 \\
\hline & Observed & 22 & 21 & 5 & 48 \\
\hline \multirow{2}{*}{$\begin{array}{l}\text { Live pups ( } 170 \\
\text { screened) }\end{array}$} & Expected & 42 & 42 & 10 & 76 \\
\hline & Observed & 35 & 36 & 0 & 99 \\
\hline
\end{tabular}


Table 2 Survival of FancC $^{-1-}$ DNA-PKCS ${ }^{3 A / 3 A}$ embryos and pups

\begin{tabular}{|c|c|c|c|c|c|}
\hline \multicolumn{6}{|c|}{$\mathrm{DNA}-\mathrm{PKCS}^{+/ 3 A} \mathrm{FanCC}^{+/-} \times \mathrm{DNA}-\mathrm{PKCS}{ }^{+/ 3 A} \mathrm{FanCC}^{+/-}$intercross } \\
\hline & & $\begin{array}{l}\text { DNA-PKCS }{ }^{3 A / 3 A} \mathrm{FancC}^{+/+} \text {or DNA-PKCS }{ }^{3 A /} \\
{ }^{3 A} \text { Fancc }^{+/-}\end{array}$ & $\begin{array}{l}\text { DNA-PKCS }{ }^{+/+} \text {Fancc }^{-/-} \text {or DNA-PKCS } \\
{ }_{3 A} \text { Fancc }^{+/-}\end{array}$ & $\begin{array}{l}\text { DNA-PKCS } 3 A / 3 A \\
\text { Fancc }^{-1-}\end{array}$ & $\begin{array}{l}\text { Other } \\
\text { genotypes }\end{array}$ \\
\hline \multirow{2}{*}{$\begin{array}{l}\text { E10.5 embryos (56 } \\
\text { screened) }\end{array}$} & Expected & 14 & 14 & 3 & 25 \\
\hline & Observed & 12 & 13 & 2 & 29 \\
\hline \multirow{2}{*}{$\begin{array}{l}\text { Live pups (106 } \\
\text { screened) }\end{array}$} & Expected & 26 & 26 & 6 & 48 \\
\hline & Observed & 19 & 22 & 0 & 65 \\
\hline
\end{tabular}
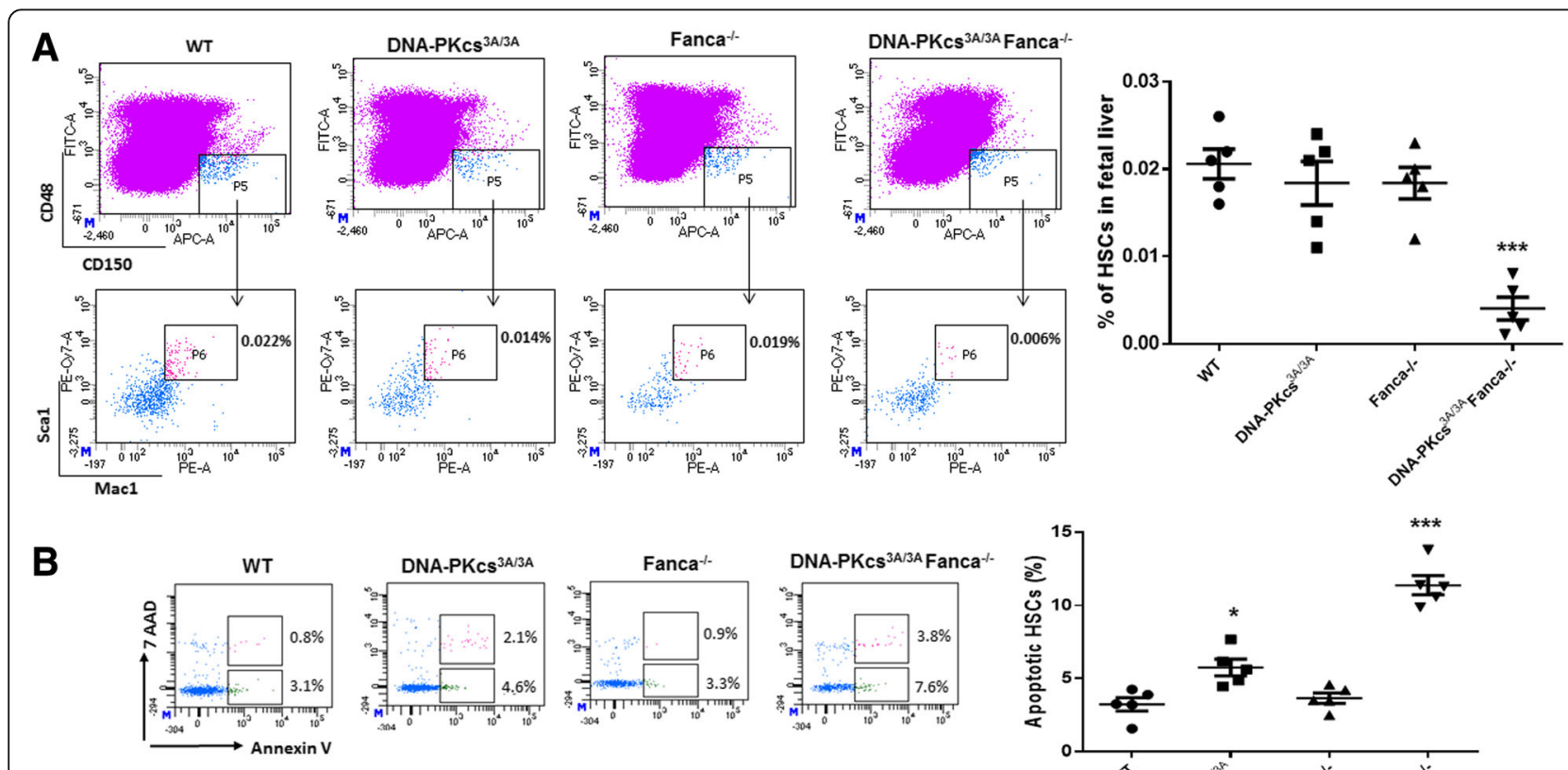

C
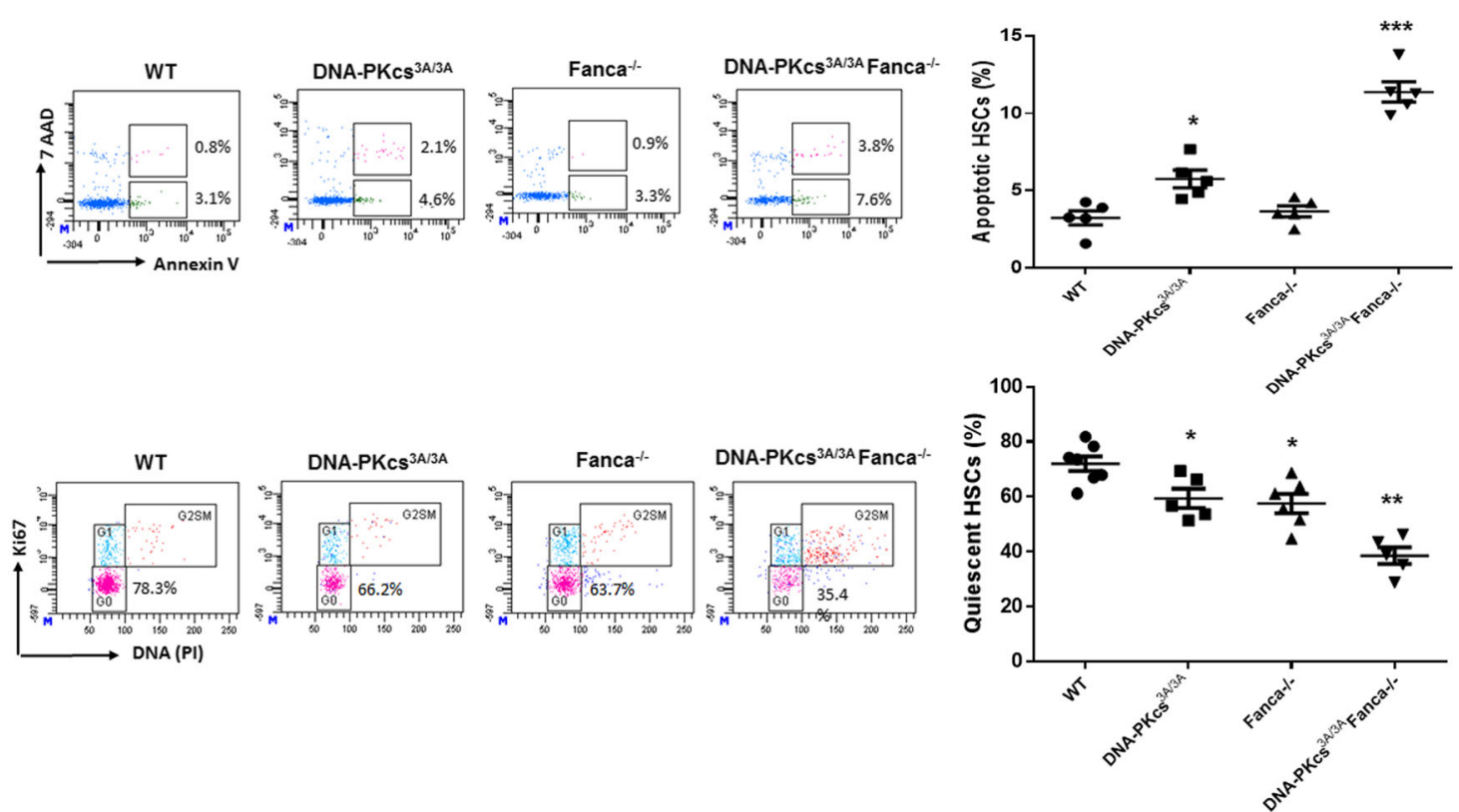

Fig. 3 Inhibition of NHEJ causes fetal HSC depletion in $\mathrm{Fanca}^{-/-}$embryos. a DNA-PKCS ${ }^{3 \mathrm{~A} / 3 \mathrm{~A}}$ induces fetal HSC depletion in Fanca ${ }^{-/-}$embryos. Fetal liver cells from E14.5 embryos with the indicated genotype were subjected to flow cytometric analysis for fetal HSC (CD150 $\left.{ }^{+} \mathrm{CD} 48^{-} \mathrm{Lin}^{-} \mathrm{Mac}^{-1} 1^{+} \mathrm{SCa}-1^{+}\right)$. Representative flow cytometric plots (left) and quantification (right) are shown. ${ }^{* * *} p<0.001$ vs WT control. b Increased apoptosis in DNA-PKcs ${ }^{3 A 3 A}$ Fanca $^{-1-}$ fetal HSCs. Fetal HSCS from E14.5 embryos of the indicated genotype were analyzed for apoptosis by Annexin V and 7AAD. Representative flow cytometric plots (left) and quantification (right) are shown. ${ }^{*} p<0.05$ or ${ }^{* * *} p<0.001$ vs WT control. c Decreased quiescence in DNA-PKcs ${ }^{3 A 3 A}$ Fanca $^{-1-}$ fetal HSCs. The percentage of quiescent $\left(G_{0}\right)$ fetal HSCs in E14.5 embryos of the indicated genotype. Representative flow cytometric plots (left) and quantification (right) are shown. ${ }^{*} p<0.05$ or ${ }^{* *} p<0.01$ vs WT control 


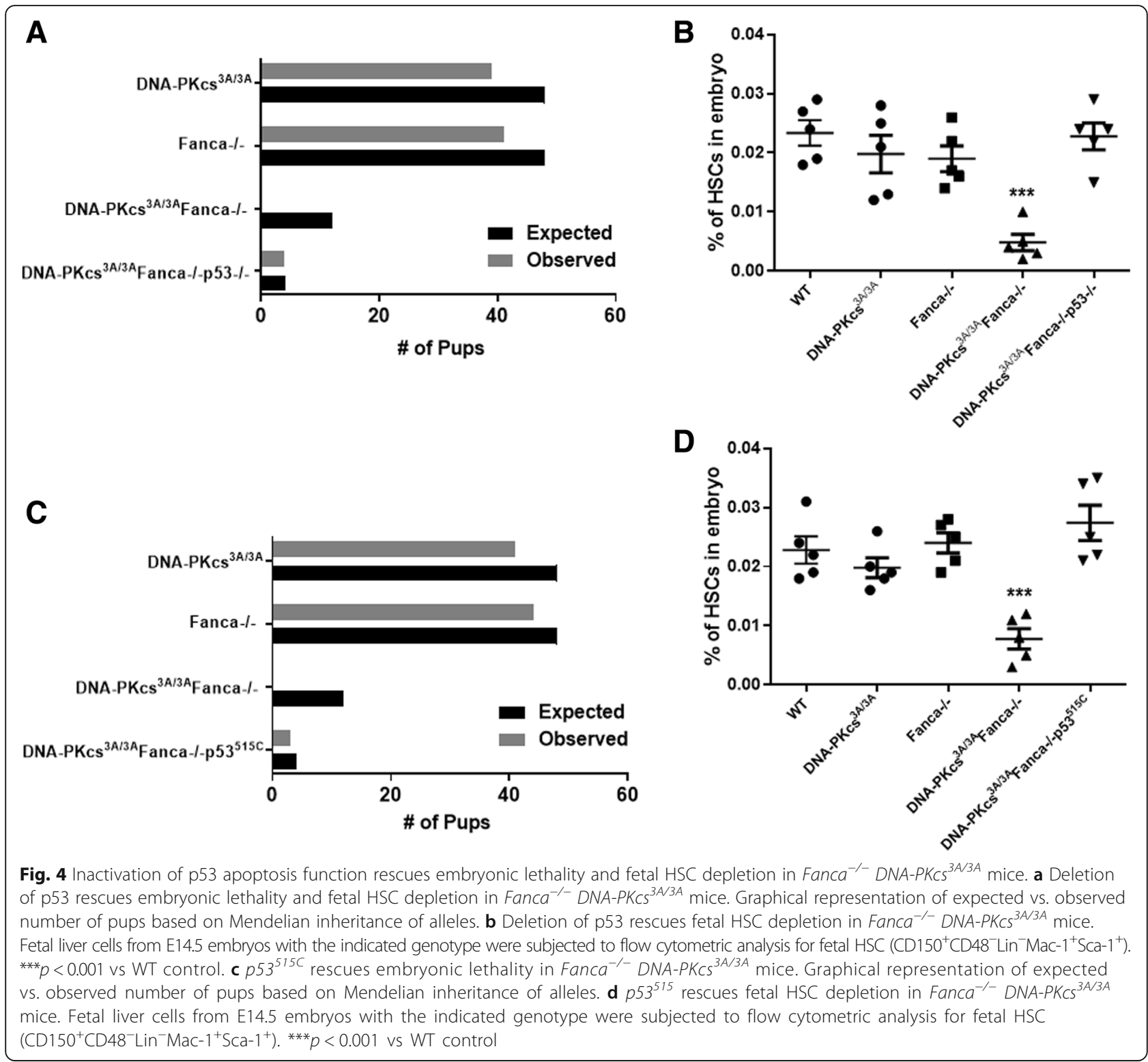

human, nematode, and chicken DT40 cells to interstrand crosslinking agents can be rescued by knockdown, deletion, or inhibition of major NHEJ proteins such as $\mathrm{Ku}$, Lig4, or DNA-PKcs. The discrepancy between these studies and ours may be due to the difference in species and cell types that were used in the experiments. It is noteworthy that the human cell lines and the chicken DT40 cells employed in the previous studies are known to utilize the HR pathway for DSB repair; whereas HSPCs in our study use the NHEJ pathway predominantly for repair of DSBs [38]. Interestingly, a more recent study shows that deletion of $K u 80$, another NHEJ factor, also causes embryonic lethality in mice deficient for Fancd2 [39].

The cause of embryonic lethality in DNA-PKcs ${ }^{3 A}$ ${ }^{3 A} \mathrm{Fanca}^{-/-}$mice may be due to fetal HSC depletion. In support of this notion, we observed significantly increased HSC apoptosis and cycling in developing embryos of $D N A-P K c s^{3 A / 3 A} \mathrm{Fanca}^{-/-}$mice compared to those of WT, DNA-PKCS ${ }^{3 A / 3 A}$ or $\mathrm{Fanca}^{-/-}$mice. It is well known that aberrantly increased cell cycling can lead to the depletion of adult HSCs, which are quiescent under normal conditions [40-42]. Our results raise the possibility that abnormally increased cell-cycle progression in fetal HSCs could also lead to their depletion. Interestingly, both p53 null and a knockin $p 53^{515 C}$ mutation, which selectively impairs only the p53 function in apoptosis, can rescue embryonic lethality and fetal HSC depletion in $\mathrm{Fanca}^{-/-}$DNA-PKCs ${ }^{3 A / 3 A}$ mice. This suggests that although $D N A-P K c s^{3 A / 3 A}$ increases $\mathrm{Fanca}^{-/-}$ HSC cycling, the cell-cycle activity of p53 is not the 
decisive factor in the regulation of DNA-PKCS ${ }^{3 A / 3 A}$ HSC maintenance. In this context, our results are consistent with previous studies that show p53-dependent apoptosis in the DNA-PKcS ${ }^{3 A / 3 A}$ HSCs and FA HSPCs $[33,37]$.

\section{Conclusions}

In this study, we employed multiple mouse models of closely related DNA damage response (FA, NHEJ, p53) pathways to demonstrate that the NHEJ pathway is required for cell survival and proliferation of murine FA HSPCs. We further show that the NHEJ pathway functions to maintain Fanconi anemia fetal HSCs.

\begin{abstract}
Acknowledgements
We thank Dr. Madeleine Carreau (Laval University) for $\mathrm{Fanca}^{+/}$mice, Dr. Manuel Buchwald (University of Toronto) for Fancc ${ }^{+/}$mice, Dr. Guillermina Lozano (University of Texas M.D. Anderson Cancer Center) for p53 $515 \mathrm{C} / 515 \mathrm{C}$ mice, Dr. Benjamin P. C. Chen (University of Texas Southwestern Medical Center) for DNA-PKcs ${ }^{3 A / 3 A}$ mice, and Dr. Lenhand Rudolph (Institute of Molecular Medicine and Max-Planck-Research, Germany) for SF-LV-shRNAEGFP vector. We also thank the Viral Vector Core of Cincinnati Children's Research Foundation (Cincinnati Children's Hospital Medical Center) for the preparation of viruses, and the Comprehensive Mouse and Cancer Core of the Cincinnati Children's Research Foundation (Cincinnati Children's Hospital Medical Center) for bone marrow transplantation service.
\end{abstract}

\section{Funding}

This investigation was partially supported by NIH grants R01 HL076712, R01 HD089932. Q.P. was supported by a Leukemia and Lymphoma Scholar award.

\section{Availability of data and materials}

The datasets used and/or analysed during the current study are available from the corresponding author on reasonable request.

\section{Authors' contributions}

YN designed and performed the research, analyzed the data, and wrote the paper. $Y L$ designed and performed the research and analyzed the data. $X L$ performed the research and analyzed the data. AFW performed the research. QP designed the research and wrote the paper. All authors read and approved the final manuscript.

\section{Ethics approval and consent to participate}

All animal procedures were approved by the Institutional Animal Care and Use Committee of Cincinnati Children's Hospital Medical Center prior to study initiation (IACUC protocol \# 2013-0159).

\section{Consent for publication}

Not applicable.

\section{Competing interests}

The authors declare that they have no competing interests.

\section{Publisher's Note}

Springer Nature remains neutral with regard to jurisdictional claims in published maps and institutional affiliations.

Received: 13 December 2018 Revised: 1 March 2019 Accepted: 3 March 2019 Published online: 29 March 2019

\section{References}

1. Bagby GC. Genetic basis of Fanconi anemia. Curr Opin Hematol. 2003;10:68-76.

2. Tischkowitz MD, Hodgson SV. Fanconi anaemia. J Med Genet. 2003;40:1-10.

3. Kennedy RD, D'Andrea AD. The Fanconi anemia/BRCA pathway: new faces in the crowd. Genes Dev. 2000;19:2925-40.

4. Green AM, Kupfer GM. Fanconi anemia. Hematol Oncol Clin North Am. 2009;23(2):193-214.
5. Dong $H$, Nebert DW, Bruford EA, Thompson DC, Joenje H, Vasiliou V. Update of the human and mouse Fanconi anemia genes. Hum Genomics. 2015;9(1):32

6. Bogliolo M, Schuster B, Stoepker C, Derkunt B, Su Y, Raams A, et al. Mutations in ERCC4, encoding the DNA-repair endonuclease XPF, cause Fanconi anemia. Am J Hum Genet. 2013;92(5):800-6.

7. Sawyer, S.L., Tian, L., Kähkönen, M., Schwartzentruber, J., Kircher, M.; University of Washington Centre for Mendelian Genomics et al. Biallelic mutations in BRCA1 cause a new Fanconi anemia subtype. Cancer Discov 5(2):135-142 (2015).

8. Knies K, Inano S, Ramírez MJ, Ishiai M, Surrallés J, Takata M, Schindler D. Biallelic mutations in the ubiquitin ligase RFWD3 cause Fanconi anemia. J Clin Invest. 2017;127(8):3013-27 PMID: 28691929.

9. Kottemann MC, Smogorzewska A. Fanconi anaemia and the repair of Watson and Crick DNA crosslinks. Nature. 2013:493(7432):356-63.

10. Deans AJ, West SC. DNA interstrand crosslink repair and cancer. Nat Rev Cancer. 2011:11(7):467-80.

11. Kim H, D'Andrea AD. Regulation of DNA cross-link repair by the Fanconi anemia/BRCA pathway. Genes Dev. 2012;26(13):1393-408.

12. Adamo A, Collis SJ, Adelman CA, Silva N, Horejsi Z, Ward JD, et al. Preventing nonhomologous end joining suppresses DNA repair defects of Fanconi anemia. Mol Cell. 2010;39(1):25-35.

13. Bunting SF, Nussenzweig A. Dangerous liaisons: Fanconi anemia and toxic nonhomologous end joining in DNA crosslink repair. Mol Cell. 2010;39(2):164-6.

14. Kee $Y, D^{\prime}$ Andrea $A D$. Expanded roles of the Fanconi anemia pathway in preserving genomic stability. Genes Dev. 2010;24(16):1680-94.

15. Pace P, Mosedale G, Hodskinson MR, Rosado IV, Sivasubramaniam M, Patel KJ. Ku70 corrupts DNA repair in the absence of the Fanconi anemia pathway. Science. 2010;329(5988):219-23.

16. Bunting SF, Callén E, Wong N, Chen HT, Polato F, Gunn A, et al. 53BP1 inhibits homologous recombination in Brca1-deficient cells by blocking resection of DNA breaks. Cell. 2010;141:243-54.

17. Krishnakumar R, Kraus WL. The PARP side of the nucleus: molecular actions, physiological outcomes, and clinical targets. Mol Cell. 2010;39:8-24.

18. McLornan DP, List A, Mufti GJ. Applying synthetic lethality for the selective targeting of cancer. N Engl J Med. 2014;371:1725-35.

19. El-Khamisy SF, Masutani M, Suzuki H, Caldecott KW. A requirement for PARP-1 for the assembly or stability of XRCC1 nuclear foci at sites of oxidative DNA damage. Nucleic Acids Res. 2003;31:5526-33.

20. Bryant HE, et al. PARP is activated at stalled forks to mediate Mre11dependent replication restart and recombination. EMBO J. 2009;28:2601-15.

21. Haince JF, et al. PARP1-dependent kinetics of recruitment of MRE11 and NBS1 proteins to multiple DNA damage sites. J Biol Chem. 2008; 283:1197-208.

22. Paddock MN, et al. Competition between PARP-1 and Ku70 control the decision between high-fidelity and mutagenic DNA repair. DNA Repair (Amst). 2011;10:338-43.

23. Jagtap P, Szabó C. Poly(ADP-ribose) polymerase and the therapeutic effects of its inhibitors. Nat Rev Drug Discov. 2005;4(5):421-40.

24. Rouleau M, Patel A, Hendzel MJ, Kaufmann SH, Poirier GG. PARP inhibition: PARP1 and beyond. Nat Rev Cancer. 2010;10(4):293-301.

25. Bryant HE, Schultz N, Thomas HD, Parker KM, Flower D, Lopez E, et al. Specific killing of BRCA2-deficient tumours with inhibitors of poly (ADPribose) polymerase. Nature. 2005:434:913-7.

26. Farmer H, McCabe N, Lord CJ, Tutt AN, Johnson DA, Richardson TB, et al. Targeting the DNA repair defect in BRCA mutant cells as a therapeutic strategy. Nature. 2005:434:917-21.

27. Shaheen M, Allen C, Nickoloff JA, Hromas R. Synthetic lethality: exploiting the addiction of cancer to DNA repair. Blood. 2011;117(23):6074-82.

28. Gottipati P, Vischioni B, Schultz N, Solomons J, Bryant HE, Djureinovic T, et al. Poly(ADP-ribose) polymerase is hyperactivated in homologous recombination-defective cells. Cancer Res. 2010;70(13):5389-98.

29. Hilton JF, Hadfield MJ, Tran MT, Shapiro Gl. Poly(ADP-ribose) polymerase inhibitors as cancer therapy. Front Biosci. 2013;18:1392-406.

30. Wong JC, Alon N, Mckerlie C, Huang JR, Meyn MS, Buchwald M. Targeted disruption of exons 1 to 6 of the Fanconi Anemia group A gene leads to growth retardation, strain-specific microphthalmia, meiotic defects and primordial germ cell hypoplasia. Hum Mol Genet. 2003;12:2063-76.

31. Chen M, Tomkins DJ, Auerbach W, McKerlie C, Youssoufian H, Liu L, Gan O, Carreau M, Auerbach A, Groves T, et al. Inactivation of Fac in mice produces 
inducible chromosomal instability and reduced fertility reminiscent of Fanconi anaemia. Nat Genet. 1996;12(4):448-51.

32. Liu G, Parant JM, Lang G, Chau P, Chavez-Reyes A, El-Naggar AK, Multani A, Chang S, Lozano G. Chromosome stability, in the absence of apoptosis, is critical for suppression of tumorigenesis in Trp53 mutant mice. Nat Genet. 2004;36:63-8.

33. Zhang S, Yajima H, Huynh $H$, Zheng J, Callen E, Chen HT, Wong N, Bunting S, Lin YF, Li M, Lee KJ, Story M, Gapud E, Sleckman BP, Nussenzweig A, Zhang CC, Chen DJ, Chen BP. Congenital bone marrow failure in DNA-PKCs mutant mice associated with deficiencies in DNA repair. J Cell Biol. 2011; 193(2):295-305.

34. Oostra AB, Nieuwint AW, Joenje $H$, de Winter JP. Diagnosis of Fanconi anemia: chromosomal breakage analysis. Anemia. 2012;2012:238731.

35. Du W, Amarachintha S, Wilson AF, Pang Q. Hyper-active non-homologous end joining selects for synthetic lethality resistant and pathological Fanconi anemia hematopoietic stem and progenitor cells. Sci Rep. 2016;6:22167.

36. Kim I, He S, Yilmaz OH, Kiel MJ, Morrison SJ. Enhanced purification of fetal liver hematopoietic stem cells using SLAM family receptors. Blood. 2006;108(2):737-44.

37. Ceccaldi R, Parmar K, Mouly E, Delord M, Kim JM, Regairaz M, Pla M, Vasquez N, Zhang QS, Pondarre C, Peffault de Latour R, Gluckman E, Cavazzana-Calvo $\mathrm{M}$, et al. Bone marrow failure in Fanconi anemia is triggered by an exacerbated p53/p21 DNA damage response that impairs hematopoietic stem and progenitor cells. Cell Stem Cell. 2012;11(1):36-49.

38. Mohrin M, Bourke E, Alexander D, Warr MR, Barry-Holson K, Le Beau MM, et al. Hematopoietic stem cell quiescence promotes error-prone DNA repair and mutagenesis. Cell Stem Cell. 2010;7(2):174-85.

39. Bunting SF, Callén E, Kozak ML, Kim JM, Wong N, López-Contreras AJ, Ludwig T, Baer R, Faryabi RB, Malhowski A, Chen HT, Fernandez-Capetillo O, D'Andrea A, Nussenzweig A. BRCA1 functions independently of homologous recombination in DNA interstrand crosslink repair. Mol Cell. 2012;46(2):125-35.

40. Orkin SH, Zon LI. Hematopoiesis: an evolving paradigm for stem cell biology. Cell. 2008;132:631-44.

41. Morrison SJ, Uchida N, Weissman IL. The biology of hematopoietic stem cells. Annu Rev Cell Dev Biol. 1995;11:35-71.

42. Orford KW, Scadden DT. Deconstructing stem cell self-renewal: genetic insights into cell-cycle regulation. Nat Rev Genet. 2008;9:115-28.

Ready to submit your research? Choose BMC and benefit from:

- fast, convenient online submission

- thorough peer review by experienced researchers in your field

- rapid publication on acceptance

- support for research data, including large and complex data types

- gold Open Access which fosters wider collaboration and increased citations

- maximum visibility for your research: over $100 \mathrm{M}$ website views per year

At $\mathrm{BMC}$, research is always in progress.

Learn more biomedcentral.com/submissions 